\title{
Institutions and Service Delivery in Asia
}

\section{Anuradha Joshi*}

\begin{abstract}
1 Introduction
This article examines some of the key challenges in the delivery of basic services of health and education to poor populations in Asia in view of reaching the Millennium Development Goals (MDGs). It highlights the institutional problems involved in the delivery of basic services and identifies some global trends including decentralisation, pluralisation and participation within which these problems are located. The article reviews some recent innovative attempts at meeting the challenges of improving access, quality and financing services for the poor. It focuses primarily on the delivery of primary health and education services. In terms of geographical coverage, the experiences discussed here are limited to those from South and South-east Asia.
\end{abstract}

The article argues that while additional financial resources for basic services will no doubt be required, the main barriers to improved services are institutional ones. Insufficient resources at the local level, absenteeism of staff, the absence of standards, lack of integration or regulation of non-state providers and neglect of the potential of nongovernmental organisations (NGOs) and the private sector have led to a state where the poor receive low-quality inadequate services. While there has been little investment in systematically evaluating impact, the range of experiences reviewed here outlines some promising approaches to improving access, quality and sustainability for reaching previously excluded populations. It argues that citizen engagement will be an important element for improving accountability and responsiveness in service delivery.

While economic growth in the Asian region has been good and has translated into some progress in poverty reduction, it has been accompanied by rising inequality, where some regions and groups are being left behind. The gains in economic prosperity also have not been mirrored adequately in the human development indicators, especially those related to maternal mortality and primary enrolment (ESCAP 2005). Several challenges emerge in the current context. The recent SARS outbreak and the threat of avian flu has underscored the need for a collective, cross-national response to potential epidemics. The rapid spread of HIV/AIDS requires new responses for prevention as well as treatment, especially given the need for effective, but expensive anti-retrovirals. Growing urbanisation has put pressures on already stretched health and education systems. In China, internal migration and the breakdown of entitlements to services is creating a large population with little access to health and education systems. In almost all countries, the growth of nonstate providers and the increasing commercialisation of services require urgent responses in the form of integration, regulation and enforcement, for example, in the case of counterfeit drugs. Finally, persisting conflict in a few countries, e.g. Nepal and parts of Sri Lanka, will continue to pose challenges for service delivery.
Simultaneously, the present period represents a unique opportunity to address these challenges as political leaders in Asia are more likely to be receptive to innovative approaches to service delivery. In healthcare, the changing demographics of populations and the rising costs of care are creating the pressures on politicians to protect populations from the impoverishing impact of major illnesses. The looming threat of an HIV/AIDS epidemic, while different in many ways from that in Africa, calls for an urgent policy response. Education is increasingly understood to underpin the success stories of economic growth and governments are under 
pressure to improve access to education for all. Strong political commitment is a consistent feature of cases of successful provision and will be necessary to initiate and sustain reforms to health and education systems.

The next section of this article discusses some of the key problems of service delivery and outlines some general trends within which service delivery operates. The third section reviews the range of attempts in Asia to improve health and education and draws lessons from successful cases. The final section outlines the challenges that remain, and suggests potential entry points for service delivery improvements and the implications of these for a range of actors, including donors and country governments.

\section{Approaches to service delivery}

\subsection{Key problems}

Prevailing problems with the delivery of basic services can be separated into three main issues.

\section{Access}

Throughout the Asian region, access to basic services continues to be an issue, although at different levels for health, education, water and sanitation. There tend to be three primary barriers to access.

First, there is the issue of the availability of physical infrastructure at a reasonable distance, a problem that is mostly confined to remote rural regions. In the health sector, until a few decades ago, a shortage of facilities, personnel, drugs and resources characterised Asian health systems. These shortages have now been more or less overcome. With a few exceptions, most people have access to a wide variety of practitioners and can obtain most drugs from local pharmacies. In education, the problem is largely restricted to remote rural areas where the state facilities are sparse and it is not yet profitable for the non-state sector to operate. In the water and sanitation sector too, the lack of physical infrastructure is largely confined to remote rural areas of low population density.

Second, there is the problem of affordability of services for the poor. Even when access to services is free, utilisation involves costs. In assessing affordability of primary education, for example, the actual costs of attending school (including uniforms, books and materials, transport and the opportunity cost of labour) need to be taken into account. When primary healthcare centres are distant from the location of the users, the costs of transportation, food and overnight stays need to be taken into account when judging affordability. Thus, distant facilities or high opportunity costs might exclude certain groups even when considered 'affordable' in general terms.

Third, and this is a challenge for most Asian countries, there is the issue of tackling social exclusion - ensuring that institutions and communities do not engage in practices that deliberately exclude access for particular groups. The groups that are excluded vary from country to country depending upon institutional and social factors. In India, caste-based exclusion dominates, whereas in Nepal, exclusion is largely based on spatial and social inequalities. In most contexts, women are responsible for the collection of water, women tend to use health services on a more continuous basis, and there are greater cultural and social barriers for girls to attend schools. Women are adversely affected by the poor design of services (ESCAP 2005). Thus, promising approaches to tackling exclusion will have to be tailored to the specific cultural and institutional context of each country with particular attention paid to the needs of women (GHK 2005).

\section{Quality}

In many countries in Asia, publicly provided basic services are of poor quality. There seem to be three key reasons for this.

First, the networks of facilities often lack basic, essential equipment and supplies. Stories abound of schools without books and materials and health posts without drugs or examination equipment. Sometimes, corruption is the culprit; for example, when drugs have been diverted for sale privately. In other cases, after the payment of staff salaries, there simply are no resources left for supplies.

Second, existing facilities are frequently poorly maintained. When key equipment breaks down, it is often not repaired. The neglect of maintenance and repair has a political logic: it is easier and more attractive for governments to raise the capital costs of creating new facilities. The variety of stakeholders - politicians, contractors and donors - for different reasons, are usually less interested in financing the 
recurring costs of operation and maintenance, making these facilities ineffective.

Third, public health and education systems are often plagued by unmotivated and absent personnel. These basic services are labour intensive. Despite the existence of adequate numbers of professionals within countries, it is difficult to recruit staff to work in remote schools or clinics. Absenteeism is high. One study of primary healthcare providers in Bangladesh found an absentee rate of 74 per cent (Chowdhury and Hammer 2003). Motivation levels among staff are low. In addition, staff are paid low salaries with inadequate resources, leading them to develop private practice and use public institutions as a source of new clients. So, for example, teachers absent from rural schools often take students for special tuition outside office hours.

Fourth, a problem that plagues both public and private providers of services is the difficulty that users face in judging the quality of services offered; this is particularly true in the case of healthcare. In the absence of alternatives, users may judge quality based on the utilisation of certain procedures (e.g. injections). These proxies for quality can distort the incentives for providers and often lead to overprescription and growth of expensive treatments. In the absence of clear indicators of quality, users become reluctant to pay for it, which can lead to a race to the bottom. In other cases it might be almost impossible for a layperson to ascertain quality, as is evident from the growing problem of the sale of counterfeit drugs. Public procurement, enforcement of regulations, public information campaigns and quality assurance through branding are some approaches to tackling quality. In education too, quality varies among non-state providers. This is particularly of concern when the poor are paying for services in the private sector. While non-profit providers are more likely to be concerned with quality, systems of accountability are lacking to ensure appropriate standards. The lack of clarity of standards and regulation in both health and education is an issue that needs to be addressed.

\section{Affordability and sustainability}

The sustainability of quality services at affordable levels is premised on a sound system of financing. There are some key issues related to financing that need to be addressed for sustainable and affordable health and education systems.
First, in some countries, there is simply inadequate public spending on basic services. For example, in Nepal and Bangladesh, per capita health expenditure is only US\$12. In Cambodia, the government spends only 3.2 per cent of gross domestic product (GDP) per capita on primary education compared with 12.5 per cent in Thailand (World Bank 2004). Partly, the problem in some countries is that basic services are not adequately prioritised. In others, e.g. Bangladesh, tax takes are low, making it difficult for governments to devote additional spending to basic services without increasing tax revenues. Clearly in many contexts, significant additional resources will be required in order to reach the poorest. Yet, if public services have been chronically underfunded, then it will take time before the results of additional resources will be seen.

Second, the level of public expenditure also depends upon a broader understanding of the role of the state in the provision of services. For example, the financing of basic primary education for poor people in Asian countries is widely accepted to be a public responsibility (Subramanian 2006). In health, there is broader acceptance of the need to pay for healthcare: countries seem to have moved away from universal free provision with the widespread introduction of user charges. User charges are expected to place health facilities on a sounder financial footing, increase incentives for staff to be responsive and generate accountability relationships among users and providers. However, there is a danger that user charges will price out certain sections of the population, particularly the poorest, from accessing services. But given that the Asian context is largely characterised by a proliferation of non-state providers, reaching the poorest and the socially excluded might best be achieved through demand-side approaches, including vouchers that stimulate both the public and the private sector to improve services.

Third, in those countries where the aggregate levels of expenditure seem adequate, resources frequently do not reach the poor. There is often bias in expenditure towards services that largely benefit the rich. For example, the education budget can be weighted towards tertiary education: in Nepal, 46 per cent of the spending on education is biased towards the richest fifth; and in India, the richest fifth receive three times the healthcare spending compared with the poorest fifth (World Bank 2004). There is also the problem of corruption: funds targeted for primary- 
level facilities never reach them. An audit of expenditures in Uganda found that only 13 per cent of the non-salary expenditure on primary education actually reached the schools (World Bank 2004).

Finally, an issue pertinent to healthcare financing is the need to develop systems of insurance that would spread the costs of healthcare over a larger population. This is especially of concern for major health episodes requiring hospital services and related high costs that can push people into poverty. Some East Asian countries have been successful in gradually extending health insurance schemes into national programmes. Mongolia initiated social health insurance with the aim of achieving universal coverage. Tax revenues funded those that were not covered through employment deductions, though such funding has been difficult to sustain (Walford et al. 2006: 23). China has recently announced that it intends to cover a high proportion of its rural population with health insurance within a few years (Bloom 2006). The challenge for governments attempting to institute universal health insurance is to set real limits on costs and establish sound management and monitoring systems. The attraction of health insurance schemes is that they enable people to share the financial risk of major illnesses and provide a mechanism to monitor and alter hospital performance.

\subsection{Prevalent approaches}

Over the past couple of decades there has been a sea change in thinking about the delivery of basic services. The earlier confidence about direct state provision has gradually given way to a more pluralistic vision of delivery through a variety of non-profit or market-based actors, the increased participation of user groups, decentralisation of services and a focus on improving incentives for providers. Increasingly, with growing incomes, services are being provided by the private sector including for-profits and nonprofits. From the 1960s and 1970s, when the state aspired to directly provide services, there is greater recognition that the role of the state is to provide public goods, finance basic services, target vulnerable populations, assure quality and regulate non-state actors. In practice, a wide variety of delivery models have been tried out including contracting out, public-private partnerships, concessions and co-production.

In this changed context, four broad trends can be identified in the efforts to improve basic services.

\section{Improving existing direct government provision}

There has been a growing recognition of the need to generate and align incentives for providers and front-line staff to improve the outcomes of service delivery. This has taken place through both supplyside approaches (better equipment, staffing, improvements in quality, and the introduction of user charges) as well as demand-side approaches (generating competition, vouchers for targeting specific constituencies etc.). In the health sector, there have been some moves towards developing insurance systems to spread risks and contain the costs of healthcare for the poor.

\section{Decentralisation}

The rationale for decentralisation has been similar. In addition to political motivations, decentralisation has been driven by the desire to improve accountability and responsiveness. Decentralisation of public provisioning gives the government a presence more directly in people's communities, easier physical access to public officials and a greater stake in improving services as a result of greater use. Almost all countries in the region have adopted decentralisation policies, with India, Indonesia, the Philippines and Pakistan going further than most, while Bangladesh, Nepal and Sri Lanka have been more incremental in their approaches. The impacts of such policies on service delivery have been mixed.

\section{Pluralisation of service providers}

There is a growing number of providers of basic health and education, both de facto - where the private sector has stepped in, either to fill a gap in public service provision - or as a matter of deliberate choice (through arrangements such as contracting, co-production and partnerships). The assumption is that the proliferation of providers will reach different target groups as well as offer choice through competition within market segments. In addition, the separation of policy making and service provision will enable policy makers to hold providers accountable through contracts etc.

\section{Institutionalisation of user participation}

Institutional mechanisms to integrate citizens' voices are now recognised as being essential for the responsiveness of services. Traditionally, service delivery has relied on formal political systems to ascertain citizens' needs. Yet, it seems clear that for many polities, political institutions mobilise people not on programmatic issues, but on other grounds such as 


\section{Box 1 Stipends for girls in Bangladesh}

A government initiative to increase the enrolment levels and achievement of girls in secondary schools started in the mid-1990s and has succeeded in achieving gender parity in enrolment. Under the initiative, the government pays a grant stipend to parents of girls and to schools where they are enrolled. The stipend is conditional based on attendance, achievement and delayed marriage. It is clear that the scaling up of the programme has been possible due to sustained political will. There are clear, performance-based incentives for all stakeholders - the government, the schools, parents and the girls. An assessment of the programme found that while able to increase enrolment, due to low achievement levels it can exclude girls from poorer families after the first year. To combat such a decline, continuous monitoring and review using disaggregated data is required. In particular, there is a need to look beyond simple access to schooling to creating an environment that meets the needs of all girls. With modifications, it offers an interesting approach to target specific groups and increase access (GHK 2005).

race, ethnic identity or religion. Increasingly, there appears to be some consensus among development scholars of the importance of direct user participation in effective service delivery. The World Development Report 2004 based its analysis on the relationships of accountability between three sets of actors - policy makers, providers and citizens. Responsiveness and accountability to the poor in particular depends, on the one hand, on the ability of the users/beneficiaries to engage in collective action. Collective action, however, is an outcome of interactions with state institutions and the incentives for citizens to engage. Thus, to the extent that service delivery systems can strengthen citizens' voices through institutionalisation, they will be more robust, responsive and sustainable (Malick forthcoming).

In response to this focus, a number of innovative experiments have been attempted throughout the Asian region to bring users into all phases of the process of service delivery. These include user committees, parent teacher associations, health facility management committees and locality-based citizen action fora. In addition to these institutional spaces for participation, there has been a growing recognition of the importance of rights-based approaches to foster collective action and claimmaking by the poor. This has been evident through the number of campaigns for the right to basic services, including the institutionalisation of such rights into constitutions in some cases, for example the right to education in India.

Yet, as is evident from the research and cases reported below, these trends and their practice in Asia have had varied impacts on service access, quality, affordability and voice for the poor.

\section{Innovations in Asia}

3.1 Improving existing government provision A number of efforts have attempted to improve existing service delivery by governments through establishing incentives for providers to improve quality and target different users.

\section{Demand-led approaches}

One response to the perceived inadequacy of government health services has been an interest in demand-side approaches. These involve the channelling of resources directly to households or third-party institutions responsible for securing services for a defined group of people. The advantages of such approaches are that they ensure resources reach the intended beneficiaries and that they strengthen institutions that can influence providers to perform better (Standing 2004). In Bangladesh, BRAC (an $\mathrm{NGO}$ ) has initiated a livelihoods approach centred on the transfer of assets to ultra poor women that along with improved knowledge and the provision of 'priority' treatment cards has improved the utilisation of government health services (Matin 2002). Similarly, under a Bangladesh government programme, the provision of stipends for girls has improved their enrolment in schooling, and reduced drop-out rates (Box 1). Demand-led approaches can also offset the exclusionary impacts of user charges as is evident from the experience of health equity funds in Cambodia (Hardeman et al. 2005).

The provision of incentives for target groups to attend schools has been another approach to improve access and tackle exclusion. A successful example of this approach is government provision of targeted performance-based school funding which provides incentives for school management committees and 


\section{Box 2 Sarva Shiksha Abhiyan}

In 2001, India launched the National Program of Universal Elementary Education, known in Hindi as Sarva Shiksha Abhiyan (SSA), and amended its constitution to make quality elementary education a fundamental right of every child. The programme is designed so that by 2007 , all children, including those with disabilities, will have completed primary schooling, and by 2010, upper primary schooling a much stiffer requirement than the MDG of universal completion of primary education by 2015.

The SSA programme combines new financing mechanisms with decentralised management, bottomup planning, community mobilisation and social audits. The central government funds 75 per cent of the costs and the states fund 25 per cent. The states are required to maintain spending for elementary education in real terms at the 1999 level in order to prevent substitution. Three external partners (the World Bank, the UK, and the European Community) contribute US\$1.05 billion to the Union Government's share.

Since its launch in 2001, SSA has had success in enrolling children who have never accessed schools and brought drop-outs back, while also improving the quality of educational inputs. Success has been achieved through central leadership and decentralised funding and management. If progress continues, the SSA will contribute to India meeting the goal of universal primary education by 2015 (Wu et al. 2005).

communities to increase enrolment of dalit (lower caste) children and girls in schools in Nepal (GHK 2005). Similarly, the mandatory Midday Meals Scheme (MMS) in India has led to improved enrolment and performance of children from poor backgrounds in many states (Gopaldas 2004). Yet a challenge for the scheme has been the prevalence of caste-based social exclusion, especially in the employment of lower castes as cooks and the provision of inferior quality food for children of lower castes. Tackling such community-based exclusion will remain a challenge for such an approach.

\section{Supply-side approaches}

Focusing on the supply of government services remains a key strategy for improvements in access and quality for many countries. The extension of facilities (schools and primary healthcare centres) is still essential, particularly to address issues of exclusion from such services for those groups who cannot afford private providers, or who do not prioritise the treatment or education of women, and for extension of preventative healthcare. It is well established that proximity of services to the poorest quintile has a significant impact on their utilisation of services. In Bangladesh, for example, the presence of a health centre in close proximity to a village is associated with the reduction of underweight children in that village, with a disproportionate positive effect on the poorest quintile (World Bank 2004). India's programme of universal primary education, Sarva Shiksha Abhiyan (SSA), was built upon the earlier District Primary Education Programme (DPEP) and has tackled the problems

\section{Box 3 Education Guarantee Scheme in Madhya Pradesh}

In 1994, the Chief Minister of Madhya Pradesh, a poor state in central India, launched the Education Guarantee Scheme (EGS) to combat the problem of high illiteracy in the state. Under the scheme, the government guaranteed a school to every village. But the scheme was demand-driven: villages wanting a school had to nominate a literate adult from the village to be trained as a guruji (traditional teacher). The government was to train the nominee and pay him/her an honorarium (not equal to a regular salary) per month. The teachers were not considered government employees, and were not expected to progress up the hierarchy of the education department. They were thus paraprofessionals, workers with limited training and remuneration - a low-cost strategy to extend services to remote areas. The scheme was immensely successful: the Gross Enrolment Rate in schools rose from 76.5 per cent in 1996 to 96.2 per cent in 2001-2. In 1998, the EGS won the Commonwealth Innovation Award (LeClercq 2003). 


\section{Box 4 Thailand's 30 baht health scheme}

In 2001, Thailand introduced universal health cover for its population under the 30 baht health scheme in an attempt to provide all citizens with affordable healthcare. Users pay just 30 baht per visit, and the poor are treated free of charge. There was a parallel shift in funding from large hospitals to primary healthcare centres with a strengthening of the referral system. Included within the scheme are treatment at the primary care facility, referral to a secondary facility if necessary, health promotion and preventative services as well as ambulance costs and prescription drugs. The scheme has achieved remarkable coverage in a short period of time - by 2004, approximately 47 million people were treated under the scheme. Together with other schemes, about 99 per cent of the Thai population is estimated to have health cover. Financing of the scheme is the main challenge, as the demand for services has outstripped the budgets of the facilities. Additional funding is going to be pumped into the scheme to cover 21 per cent of the salaries of the healthcare staff (Towse et al. 2004).

with supply of schooling and managed to lever central government, state government and donor funds in a comprehensive manner to address the problems of schooling access and quality (Box 2). The Basic Primary Education Project (BPEP) in Nepal has built on earlier success of its Cheli-Beti programme that focused on the education of the girl-child and used a non-formal approach to education (Fennell 2006).

Another approach, particularly to problems of staffing and absenteeism, has been to create a cadre of para-professionals to deal with the problems of the shortage of qualified staff and their willingness to serve in remote locations. Para-professionals, consisting of locally hired and trained personnel, cost less and are less prone to absenteeism. Using paraprofessionals also enables governments to tackle the problem of access at a larger scale, as is evident from the success of the Education Guarantee Scheme (EGS) in Madhya Pradesh (Box 3). Examples of success in using para-professionals to tackle absenteeism, motivation and quality abound in the region. In India, a partnership between the government and an NGO in two cities led to the hiring of local women to teach catch-up classes for students who were falling behind. The programme was found to be effective at boosting learning, particularly among poorer children, at very low additional costs (Banerjee et al. 2003). Similarly, the Lady Health Worker Programme (LHWP) in Pakistan, which hired and trained local women for extending family planning services to the doorstep of rural women, was found to be successful (Douthwaite and Ward 2005). Yet, while the use of local female workers is found to improve access and quality of services for women, such workers are also difficult to recruit, train and retain for a variety of reasons, as was seen in Pakistan (Mumtaz et al. 2003). The experience with such initiatives also suggests that the biggest challenge to the use of paraprofessionals is opposition from teacher and health worker unions, and that strong political commitment is needed for success. Further, issues of ensuring quality of service remain a challenge and this approach needs to be coupled with periodic training and monitoring of such staff.

The charging of formal and informal user fees is a barrier to poor people accessing services. Carefully targeted subsidies for poor people, perhaps through demand-side approaches, can achieve the objective of improving services as well as preventing exclusion. Thailand's 30 baht health scheme is such a case; an innovative attempt at providing universal care at reduced costs, making it affordable for the poor through subsidies (Box 4).

The range of experiences highlighted above suggests that improving the quality of services provided through existing public facilities remains a viable strategy in many countries. While innovative strategies such as demand-led approaches, provision of incentives to include target groups and hiring of para-professionals can have positive results in many circumstances, the challenge of ensuring quality remains.

\subsection{Decentralisation}

Although decentralisation processes are under way in most Asian countries, decentralisation can be used to mean different things in different contexts depending upon whether administrative, financial or political powers are devolved. At one extreme, decentralisation can be limited to administrative structures - commonly termed 'deconcentration'. At 
the other extreme, decentralisation can mean the devolution of full control of state institutions by democratically elected local bodies - commonly termed democratic decentralisation. In general, the experience with the range of possibilities in between suggests that the impacts of decentralisation on service delivery are mixed, and depend upon a number of factors that characterise the local context (Behrman et al. 2002).

\section{Deconcentration}

The devolution of resources, responsibility and authority to local administrative structures is one approach to the improvement of services that has been tried with mixed success. By improving local control over the management of facilities, schools and health centres are expected to be more responsive to local needs and demands. Evidence suggests that local control over management of facilities can have mixed impacts on performance. In a study on local control over management of schools in Thailand, Gamage and Sooksomchitra (2004) reported that quality of education improved with greater involvement of stakeholders. In the Philippines, early data suggest that decentralisation in the health sector can exacerbate inequities, weaken local commitment to priority health issues and decrease effectiveness by disrupting the referral chain (Grundy et al. 2003). Similar findings from the decentralisation of health services in Lao PDR led the government to undertake recentralisation of the health system, resulting in improved utilisation of public health services (Phommasack et al. 2005).

\section{Democratic decentralisation}

The impact of decentralisation of responsibility of services to locally elected bodies can vary - there appears to be no clear correlation in the literature between democratic decentralisation and improved services in terms of quality, access, voice or sustainability. An examination of the impact of decentralisation of education and primary healthcare in India suggests that indicators of democratic decentralisation (frequency of elections, political participation, and presence of NGOs) have generally positive effects on services, although not statistically indistinguishable from zero (Mahal et al. 2000). In contrast, a study of the impact of decentralisation of primary healthcare centres in Kerala found that decentralisation brought no significant change to the health sector (Varatharajan et al. 2004). In some cases examined by the study, panchayats (locally elected bodies) allocated a lower proportion of resources to health than that allocated by the state government prior to decentralisation. Active panchayat support for primary healthcare centres existed only in a few cases; however, when it did, the result was positive.

These experiences suggest that decentralisation poses particular challenges for service delivery due to the differences in capacity and resources among local governments, the need for some centralised monitoring, constraints on targeting the poor given possibilities for elite capture thus exacerbating inequalities, and the possibility of weak local commitment to prioritise health and education issues. Specifically, the appropriate delivery of basic services depends upon decentralised systems being well linked to working and capable systems at higher levels - for example, a streamlined referral system for healthcare. It appears that the impact of decentralisation on service delivery will depend to some extent on (a) the priority accorded to the service at the local level by the elected leaders, (b) the availability, quality and affordability of alternative providers in the public sector, and (c) the extent to which the interests of the poor and nonpoor overlap in terms of improved services. Strengthening the voices of marginalised groups in the delivery of services is an important factor in addressing some of these challenges for decentralised delivery.

\subsection{Pluralisation}

Throughout the Asian region, the limits of government capacity and the global shift away from state involvement in direct provision has led to a variety of arrangements in which non-state providers, NGOs and for-profit organisations are gaining an increased role. In the health sector, the sale of drugs and medical testing through the private sector has grown enormously; while this provides cheap access to medicines and testing services, there are serious concerns about quality and related drug resistance issues. In some countries, the corporate sector is playing an increased role, for example the involvement of $\mathrm{ICICl}$ Bank and Wipro Technologies in India in supporting government initiatives to extend enrolment. The emergence of such pluralistic systems for health and education services highlights the extent to which governments need to respond appropriately to issues of partnerships and regulation of quality and access for the poor. 


\section{Box 5 Contracting for public healthcare in Cambodia}

In the mid-1990s, when Cambodia emerged from a long war and political upheaval, its health services were in disarray, especially in rural areas. To address these issues, the Ministry of Health with the help of an Asian Development Bank (ADB) loan contracted NGOs on a large scale to improve healthcare coverage. Systematic collection of data on contracted out (where NGOs had full control over service delivery), contracted in (where NGOs provided management support but existing government staff and financing were used) and government provision (control districts) before and after the contracting enabled a comparison of its effects on utilisation of healthcare services, particularly by the poor. Evaluations indicate that healthcare utilisation has improved considerably in both contracted-out and contracted-in districts, with a disproportionate increase in use by the poor. Simultaneously, total family expenditures on healthcare have reduced. The experience suggests that contracting with NGOs offers a way of improving quality and increasing coverage. Successful contracting, however, requires clear and objectively verifiable indicators and performance targets, political support for contracting at central and local levels, civil service arrangements that allow government health workers to work for NGOs at market rates, and flexibility for NGOs to manage in pursuit of outcomes.

Source Schwartz and Bhushan (2004); Bhushan and Schwartz (2004).

\section{Partnerships}

Working in partnership with a variety of providers can enable governments to reap the benefits of the private sector - increasing the efficiency of resource use, leveraging private sector funds, improving the motivation of front-line staff and targeting particular groups. Partnerships can be established with nonprofit or for-profit providers. The education, health, water and sanitation sectors all have several examples of successes in which NGOs have worked in partnership with public agencies to improve access to services for specific marginalised groups. For example, the Women's Health Centre Project in Mumbai, involving an NGO-municipal government partnership, established a counselling centre within the obstetrics and gynaecology ward of a public hospital (GHK 2005). It has been successful in increasing the capacity of the health system to respond to women's unmet needs in reproductive health. Residential care centres for migrant workers' children developed by ActionAid in conjunction with the Orissa government have been successful in meeting the education needs of a hitherto unserved group of children (GHK 2005). These residential centres offer a stable environment for the children both at the source and destinations of migration.

In other cases, NGOs have helped increase the coverage and quality of public services through a coordinated strategy. For example, the experience of the Pune Sanitation Programme in India suggests that NGOs can successfully produce and operate public toilets with universal coverage for low-income settlements at a cost below that usually paid to for- profit providers. Such a strategy involves establishing and institutionalising procedures for engaging with NGOs. It also requires skilful politicking by reformers and mechanisms for holding NGOs accountable.

The experience of contracting for healthcare management in Cambodia is another successful example (Box 5). However, the transferability of Cambodia's experience to other countries in the region is limited, especially in countries where NGOs are not already present on a large scale.

Clearly, with the growing number of private sector providers in health and education services, governments need to find ways of integrating them into health and education systems in order to tap their potential. In the case of partnerships with the non-state sector, the challenge for governments is to generate capacities for appropriate tendering, monitoring, enforcement and sanctioning of contracts (Mills and Broomberg 1998). In the case of integration into the overall system of service delivery, states will have to work with non-state providers to ensure that services are of adequate quality and that excluded populations are reached. Careful thought is needed to tailor transitions and points of interaction between state and non-state providers, for example through referral systems in health or transitions to formal education from non-formal systems.

\section{Regulation}

In most countries in Asia, there are now a wide variety of private, non-state providers of health and education services. Many of these have arisen due to 


\section{Box 6 Pakistan's Greenstar Network}

The Greenstar Network promoted by Population Services International (PSI) has become one of the largest developing country private reproductive health networks in the world. It consists of more than 12,000 trained private health providers, including doctors, chemists and family health visitors, who have been trained in reproductive health services and management of sexually transmitted infections and given access to subsidised products and services through the Greenstar logo. Quality is maintained through consistent monitoring, training and follow-up surveys. The Greenstar logo is widely known to provide reliable services of consistent quality and has managed to reach a significant portion of the population. A large proportion of the users of Greenstar Network are the poor, and it delivers approximately 25 per cent of estimated contraceptive coverage in Pakistan.

www.psi.org/resources/pubs/gstarl.html

the demand for high-quality care by the rich. $A$ wide array of private schools, universities, clinics and hospitals provide a diverse mix of quality and price for this segment of the population. In many countries, private providers account for a significant proportion of healthcare provision. In India, for example, 80 per cent of households use the private sector for treatment of minor illnesses. Traditional and alternative systems of medicines are also popular although the levels of qualification and regulation of providers varies significantly. In the education sector, education for the poor by non-state providers has been dominated by faith-based institutions (e.g. madrasas in Pakistan) or by NGOs. Yet increasingly, non-state, for-profit providers are emerging to cater for the poorer (but not the poorest) groups that offer schooling with minimal infrastructure, but at affordable prices (Tooley 2001).

While the growing numbers of non-state providers have an important role to play in making services available universally, their proliferation raises important challenges for establishing standards and assurance of quality. There has been little experience with successful regulation of private providers on a large scale given the resource and capacity constraints of states for monitoring and enforcement, and this is an area that needs further research. The emerging roles of the private sector and the possibilities for integration, partnership and regulation need to be mapped out for various countries to assess competencies and potential contributions.

\section{Branding}

A promising approach that has worked in Latin America (Newbrander et al. 2000) and more recently in Pakistan is through branding and voluntary codes of service that non-state providers can sign up to, thus assuring a minimum level of quality, leaving the enforcement of these codes to sector-wide associations (Box 6). Large-scale public education campaigns are a central part of such successes.

\subsection{Empowering citizens}

The growing realisation of the importance of the role of users and citizens in holding governments to account for the delivery of basic services has led to a range of initiatives attempting to empower users and provide them with institutionalised spaces for participation. These range from user committees for local management of resources in various sectors to the creation of formal policy councils (e.g. the health councils in Brazil) that offer legitimate space for direct involvement in policy making and service delivery.

\section{Institutionalising participation}

Creating institutional spaces for direct participation of users and citizens is an increasingly popular measure for simultaneously empowering citizens, and making services more responsive to users. Citizen involvement can take place at various stages, from policy formulation to citizen monitoring accountability. Citizen involvement in planning processes at the local level is an essential component of getting providers to respond to the needs of poor citizens. Janagraha, an NGO in Bangalore, India, has mobilised citizens to engage with formal spaces of participation provided in the form of ward committees. Janagraha facilitates citizen involvement by providing information, building capacities and facilitating discussions. Yet, a feeble response from government agencies and opposition from politicians has limited the impact this initiative has had. 
In both health and education, facility-level platforms have been developed that include providers, policy makers and users to help improve the management of facilities, and these have had better success. For example, hospital-level Rogi Kalyan Samitis (RKS) in Madhya Pradesh were established in district hospitals as a way of using existing assets efficiently and raising additional revenues for improving maintenance and operations. By involving politicians, prominent citizens, users, staff and administration in the RKS, the state of several hospitals has improved. Yet, the extent to which these improvements have benefited the poor is under question, especially as with the improvements, middle-class citizens who previously opted for private health providers are returning to avail of the improved services in public hospitals, thus perhaps crowding out the poor (Goetz and Jenkins 2003).

Involving citizens in the monitoring of services has also been relatively successful. The Citizen Report Cards pioneered by the Public Affairs Centre in Bangalore, India, can be a powerful way of naming and shaming poor service providers and bringing pressure on all to improve their performance (Paul 1998). Social audits such as the public hearings carried out by the Mazdoor Kisan Shakti Sangathan (MKSS) in Rajasthan can have a similar effect by highlighting the gaps between plans and implementation and holding politicians and bureaucrats accountable (Goetz and Gaventa 2001).

\section{Rights-based approaches}

Some countries and donors have experimented with rights-based approaches for improving citizen voice. By framing the service delivery discourse from basic needs to claims and rights, several conceptual shifts are accomplished. There is an implied emphasis on agency on the part of the poor (in terms of claiming individual rights and the duty of civic participation). $A$ rights-based approach also attempts to highlight issues of power and the political struggles through which rights are likely to be gained. A central theme of such approaches is that rights are not hierarchical but interrelated and interdependent - in other words, social and economic rights are not secondary to civil and political ones (Nyamu-Musembi 2005; Moser and Norton 2001).

Such rights-oriented discourse can get governments to accept responsibility for the provision of basic services. For example, in India, it played an important part in the constitutional amendment that provides the right to education (Mehendale 2005). Similarly, the right-to-health campaign attempts to focus attention on the inadequate quality of healthcare for the poor in rural and urban India by holding public hearings on quality of care, affordability and exclusion (Mehta 2005). Central to these initiatives was the role that credible information played in getting issues highlighted and people mobilised. While institutionalisation of legal rights can be problematic when governments do not have the resources to deliver on those rights, a collective approach to rights can be promising. ${ }^{2}$ If institutionalised, legal rights to health and education can catalyse fundamental reforms required in health and education

Supporting such citizen empowerment initiatives from a diversity of perspectives is an important way of channelling civil society resources into the improvement of services in both health and education.

\section{Key issues and lessons}

Service delivery is not only dependent upon good governance and institutions but can also be an entry point towards building effective states, particularly in places where states are weak. Credibility, legitimacy and effectiveness built through effective delivery of services can lead citizens to re-engage with the state and can be a path towards a virtuous cycle of engagement and accountability in the broader political sphere. Here, the location and exercise of public authority (the state) can be separated from particular governments in power. The effective delivery of basic services can reaffirm confidence in public authority, whether vested in the government or non-governmental actors. Service delivery can lead to governance dividends.

Improving services and reaching the MDGs in the areas of health, education, water and sanitation, however, will require concerted effort on the part of governments, donors, non-state actors and citizens. The experiences reviewed here suggest that it is possible to make significant progress in universal coverage if governments are committed and open to new approaches for reaching their objectives.

There are several challenges posed by the current context, particularly in the arena of healthcare, the tackling of which requires efforts beyond reforming 
health delivery systems. Increasing mobility and the concentration of populations poses potential threats of pandemics that call for cross-sectoral and global responses, e.g. increased regulation. Similarly, the rising number of health problems caused by environmental pollution, e.g. the increase in the prevalence of respiratory diseases, again will require countries to act in arenas other than the delivery of healthcare. The growing prevalence of counterfeit drugs and their impact on the poor means that governments will have to improve regulation and monitoring systems. In the coming decade, Asian countries will have to respond to these challenges in addition to some of the basic persistent problems identified earlier.

\subsection{Entry points}

Given that the experiences reviewed here suggest several promising efforts by many Asian countries, what are some of the potential entry points for action? There seem to be six key fronts on which action is essential.

\section{Strategic improvement of existing services}

Where the poor have a choice among multiple providers, including government services, governments ought to focus strategically on quality improvements in arenas important for key public objectives through both supply and demand-side approaches. For example, public agencies can focus on tackling maternal mortality or preventive healthcare through improvements in existing facilities and delivery systems by increasing the availability of trained birth attendants and access to emergency hospital care. Testing and treatment for HIV/AIDS can be an important focus for governments which can collaborate on some services with NGOs. Lessons from the range of innovations to create incentives for public organisations can be used to improve the quality of such strategic services. A major lesson here is to build on what is working in particular contexts by exploring opportunities to scale up, for example, in the provision of universal primary education.

Yet, large-scale reforms of the kind needed by many health and education systems are likely to face opposition from vested stakeholders such as professional associations (of doctors or engineers, for example) as well as public sector unions which can sabotage reform efforts. It will be important to engage and negotiate reforms in an inclusive manner in order to prevent active opposition that can derail reform efforts.

\section{Working with diverse providers}

Pluralisation is likely to be the continued context for the provision of basic services in the next few decades, as income levels rise and non-state actors respond to demands for such services. Many Asian country governments are already working with a variety of non-state providers. However, in several places, such non-state providers are poorly understood and often unrecognised. Recognition of, engagement with and strategic support for the diversity of existing providers will be essential for increasing the coverage of health, education, water and sanitation services. Experience suggests that such strategic engagement seems easier where the state is not significant as a direct provider and where nonstate actors are already attempting to fill the gap. This implies a greater emphasis for public agencies to develop capacities to engage with diverse actors, negotiate policy consensus and hold providers accountable. Dialogue and interaction with collective actors in the private sector, including intermediate organisations such as professional and sectoral associations, will be critical to such engagement. Identifying the strengths and weaknesses of various types of non-state providers will help identify where the gaps in service provision exist and why. Facilitating non-state providers to extend the reach of the public sector and enable universal and quality coverage at affordable prices will be an essential step.

\section{Regulating the non-state sector}

Effective regulation of the diverse non-state sector will be a key feature of successful health systems in Asia in the future. The quality of services delivered by non-state providers varies enormously. Competition among providers, where it exists, will not necessarily ensure quality - it can facilitate a race to the bottom. Minimum standards will need to be established so that the poor do not end up receiving poor services. Regulating the largely unregulated sectors of nonstate health and education provision for poor people is an urgent task for governments. Improved regulation and quality control and related enforcement will increase utilisation of services as well as lower expenditures on health and education. Involving stakeholders in the early phases of setting standards will be necessary to ensure buy-in during implementation. There is a need to learn from models of regulation that work in other parts of the developing world as well as the industrialised countries. There is a potential role here for developing branding and franchising as means of setting quality. 


\section{Tackling social exclusion}

The exclusion of particular groups - religious minorities, scheduled castes, women, the disabled, and the elderly among others - will continue to pose a problem for achieving universal coverage. While there are some success stories that point to a variety of ways through which services could be better targeted, fundamental constraints of institutional bias and community cultures will have to be tackled for progress on a more substantial scale. The role of the state here is likely to be offering incentives to providers for serving target populations, e.g. through demandside approaches such as school vouchers or supply-side approaches such as the provision of midday meals and the abolition of fees for service. The processes and manifestation of social exclusion vary in each context, yet in most countries services will have to be better tailored to the needs of women.

\section{Empowering poor citizens}

Empowering poorer citizens to make collective demands and stake claims will be key to improving service delivery. As evidenced from this article, a range of strategies can be employed in order to support citizen engagement from creating institutionalised spaces for direct participation to

\section{Notes}

* With thanks for contributions from Gerry Bloom and Ramya Subramanian and research assistance from Will Prichard.

1 Wipro Technologies is a leading IT company based in India - one of the software success stories and fast becoming an important corporate actor. $\mathrm{IClCl}$ Bank is a rapidly growing Indian bank that has recently expanded overseas including the UK.

\section{References}

Banerjee, A., Cole, S., Duflo, E. and Linden, L. (2003) Improving the Quality of Education in India: Evidence From Three Randomized Experiments, Cambridge, MA: Massachusetts Institute of Technology, Department of Economics

Behrman, J., Deolalikar, A. and Soon, L.-Y. (2002) Promoting Effective Schooling Through Education Decentralization in Bangladesh, Indonesia and the Philippines, ERD Working Paper Series 23, Manila: Asian Development Bank

Bhushan, I. and Schwartz, J.B. (2004) 'Improving Immunization Equity Through a Public-Private Partnership in Cambodia', Bulletin of the World Health Organization 82.9 support for rights-based approaches to social services. Generating incentives for collective action by poor people will be necessary in order to persuade the poor to organise to influence services.

\section{Building common interests}

Services that are only intended to serve the poor tend to rapidly become poor services. Exit of the middle classes from public services can reduce state commitment and lead to a downward spiral - this is especially a danger in contexts where alternatives exist. Several of the successful examples highlighted in this article point to the importance of understanding the political economy of service delivery in particular contexts. The lessons from the examples offered here can offer pointers to what might work, but the innovations need to be tested against the politics of particular contexts. For example, making public grant funding of schools partially dependent upon their enrolment of dalit (lower caste) children in Nepal provided communities with incentives to actively seek such enrolment. In general, institutional structures that build common interests between the poor and the better off are more likely to lead to quality improvements that are sustainable in the long run.

2 Thus, some have argued for a progressive realisation of social and economic rights. For example, in South Africa, the right to housing is evaluated against the government's progress towards achieving this right for all, rather than whether a particular household has been able to claim the right.

Bloom, G. (2006) 'Briefing Notes on Financing Health Care for the Poor', mimeo, Brighton: IDS Chowdhury, N. and Hammer, J. (2003) 'Ghost Doctors: Absenteeism in Bangladeshi Health Facilities', background paper for World Development Report 2004

Douthwaite, M. and Ward, P. (2005) 'Increasing Contraceptive Use in Rural Pakistan: An Evaluation of the Lady Health Worker Programme', Health Policy and Planning 20.2: 117-23

ESCAP (2005) A Future Within Reach: Reshaping Institutions in a Region of Disparities to Meet the Millennium Development Goals in Asia and the Pacific, UN Economic and Social Commission for Asia and the Pacific 
Fennell, S. (2006) 'Future Policy Choices for the Education Sector in Asia', draft paper for Asia 2015 Conference: Promoting Growth, Ending Poverty Gamage, T. and Sooksomchitra, P. (2004)

'Decentralisation and School Based Management in Thailand', International Review of Education 50.3 289-305

GHK (2005) 'Tackling Social Exclusion in Health and Education in Asia', mimeo

Goetz, A.-M. and Jenkins, R. (2003) 'The Politics of Pro-poor Policies in Andhra Pradesh and Madhya Pradesh', mimeo

Goetz, A.-M. and Gaventa, J. (2001) Bringing Citizen Voice and Client Focus into Service Delivery, IDS Working Paper 138, Brighton: IDS

Gopaldas, T. (2004) 'Improving School Education through Linking Public Health Objectives with Mid Day Meals', paper presented at conference on Reforming Governance, Centre for Public Policy, Indian Institute of Management (IIM), Bangalore

Grundy, J., Healy, V., Gorgolon, L. and Sandig, E. (2003) 'Overview of Devolution of Health Services in the Philippines', Rural and Remote Health 2, http://rrh.deakin.edu.au

Hardeman, W., Van Damme, W., Van Pelt, M., Por, I., Kimvan, H. and Meessen, B. (2005) 'Access to Health Care for All? User Fees Plus a Health Equity Fund in Sotnikum, Cambodia', Health Policy and Planning 19.1: 22-32

LeClercq, F. (2003) Education Policy Reforms and the Quality of the School System: A Field Study of Primary Schools in Madhya Pradesh, India, DIAL Working Paper, Paris: DIAL

Mahal, A., Shrivastava, V. and Sanan, D. (2000) Decentralization and Public Sector Delivery of Health and Education Services: The Indian Experience, ZEF Discussion Papers on Development Policy 20, Bonn: Center for Development Research

Malick, B. (forthcoming) Citizen Voice and Client Power: How to Build Effective and Sustainable Accountability in Urban Services, report for the Water and Sanitation Programme, mimeo, New Delhi: World Bank-UNDP (United Nations Development Programme)

Matin, I. (2002) Targeted Development Programmes for the Extreme Poor. Experiences from BRAC Experiments, Chronic Poverty Research Centre Working Paper 20, Manchester: IDPM/CPRC

Mehendale, A. (2005) Right to Education and Constitutional Amendment: A Case of India, report for Global Development Network (GDN) Bridging Research and Policy Programme
Mehta, A. (2005) Small is Beautiful: Participatory Planning in Urban Kerala, report for the Water and Sanitation Programme, New Delhi: World Bank-UNDP (United Nations Development Programme)

Mills, A. and Broomberg, J. (1998) Experiences of Contracting: An Overview of the Literature, Technical Paper 33. Geneva: World Health Organization Moser, C. and Norton, A. (2001) To Claim Our Rights, London: Overseas Development Institute

Mumtaz, Z., Salway, S., Waseem, M. and Umer, N. (2003) 'Gender-Based Barriers to Primary Health Care Provision in Pakistan: The Experience of Female Providers', Health Policy and Planning 18.3: 261-9

Newbrander, W., Cuellar, C.J. and Timmons, B.K. (2000) The PROSALUD Model for Expanding Access to Health Services, Boston: Management Sciences for Health

Nyamu-Musembi, C. (2005) 'An Actor-oriented Approach to Rights in Development', IDS Bulletin 36.1: 41-51

Paul, S. (1998) Making Voice Work: The Report Card on Bangalore's Public Services, Policy Research Working Papers, Washington DC: World Bank

Phommasack, B., Oula, L., Khounthalivong, O., Keobounphanh, I., Misavadh, T., Loun, Oudomphone, P., Vongsamphanh, C. and Blas, E. (2005) 'Decentralization and Recentralization: Effects on the Health Systems in Lao PDR', Southeast Asian Journal of Tropical Medicine and Public Health 36.2: 523-8

Schwartz, J.B. and Bhushan, I. (2004) Cambodia: Using Contracting to Reduce Inequity in Primary Health Care Delivery, HNP Discussion Paper, Reaching the Poor Programme Paper 3, Washington DC: World Bank

Standing, H. (2004) Understanding the 'Demand Side' in Service Delivery, Issues Paper, London: Department for International Development Health Systems Resource Centre

Subramanian, R. (2006) 'Education Access: Patters and Trends in the EFA Period', mimeo, Brighton: IDS

Tooley, J. (2001) 'Entrepreneurs in School Education', paper presented at the National Conference on Primary Education, New Delhi, 11-13 December

Touse, A., Mills, A. and Tangcharoensathien, V. (2004) 'Learning from Thailand's Health Reforms', British Medical Journal 328: 103-5

Varatharajan, D., Thankappan, R. and Jayapalan, S. (2004) 'Assessing the Performance of Primary 
Health Centres under Decentralized Government in Kerala, India', Health Policy and Planning 19.1: 41-51

Walford, V., Pearson, M., Eliya, R.R. and Fernando, T. (2006) 'Future Policy Choices for the Health Sector in Asia', draft paper for Asia 2015

Conference: Promoting Growth, Ending Poverty
World Bank (2004) World Development Report 2004: Making Services Work for Poor People, Washington DC: World Bank

Wu, K.B., Kaul, V. and Sankar, D. (2005) 'The Quiet Revolution', Finance and Development 42.2: 29 